\title{
CROWDSOURCING AS A CHALLENGE FOR ADVERTISING AGENCIES IN THE CREATIVE SERVICE MARKET
}

\author{
ANNA SZWAJLIK \\ University of Szczecin, POLAND \\ e-mail: anna.szwajlik@wzieu.pl
}

\begin{abstract}
RECEIVED
4 August 2017

ACCEPTED

15 December 2017

JEL

CLASSIFICATION

Q31

KEYWORDS

advertising services, crowdsourcing, crowdsourcing platforms

ABSTRACT

The article contains theoretical deliberations concerning the usage of crowdsourcing platforms in order to obtain creative resources necessary to design advertising services. The article also aims at defining what role crowdsourcing can play in the creative service market. The first part of the article presents the characterization of advertising as creative services and the role of crowdsourcing in gaining creative ideas. The concept of crowdsourcing platforms used as a way of gaining creative resources and creating ideas constituting the basis of the offered advertising services was presented in the form of examples in the next part of the article.
\end{abstract}

\section{Introduction}

Crowdsourcing as an effective concept of leveraging dispersed resources from a crowd has been used in various fields of activity. This also applies to advertising services performed by advertising agencies in the creative service market. Activities of advertising agencies are focused on providing buyers with creative ideas in order 
to highlight their products and services in the market. The descried situation creates the need for an advertising agency to obtain the access to creativity resources and is a major challenge for its business tasks.

The aim of the article is to indicate the development potential of advertising services using crowdsourcing, as well as to characterize entities applying the indicated concept in business practice.

The paper uses the methods of literature review, analysis of exemplary crowdsourcing platforms and synthesis.

\section{The role of crowdsourcing in the creative service market}

Advertising services belong to the creative service sector and are offered by companies that derive income from the sale of their time and transfer of the rights to their intellectual property to other businesses entities or organizations. Advertising services, being creative services, are characterized by the following set of attributes:

- a significant importance of creativity in the creation of advertising service core,

- an innovative work conceived as a result of a creative specialist's work,

- no possibility to objectify the performed activities and effects of service process related to them,

- the competencies of professionals are based primarily on unique abilities and gathered experience.

Entities performing advertising services are required to possess specific competencies in the scope of creation and performance of creative ideas in various areas of promotion and image-building activities. According to the American Association of Advertising Agencies, advertising agencies that act as entities offering creative services are independent organizations gathering creative and entrepreneurial people who specialize in preparation and realization of promotional plans and tools (Wiktor, 2001). Entities operating in the advertising service market can be distinguished from others by:

- the scope of the service offered and the degree of specialization,

- type of customer serviced,

- the organization's structure and number of employees.

Therefore, for many years the creative service market has been characteristically divided between global advertising companies whose clients are international brands, and smaller, specialized local advertising agencies. Global advertising companies have in their organizational structures departments responsible for delivering creative ideas and solutions. Apart from the employed specialists, creative departments, may if needed, benefit from the work of independent designers. Moreover, cooperation is underpinned by outsourcing, while the individual designers create, among others, graphic designs, advertising messages, name, and corporate logos based on precisely defined expectations. The scope of works depends primarily on advertising activity. However, it should be noted that the number of designers cooperating with an agency is usually limited and that competencies are strictly defined and verified. The added value offered by global advertising agencies is enriching the core of an advertising service with additional services, such as advising on the selection of marketing strategies, market research, including preliminary tests of developed projects, and supervision of the implementation of developed ideas. The extensive offer of additional services allows such agencies to keep attractive brands in an order portfolio.

In case of the latter group, i.e. small local agencies, it is expensive to maintain a bigger group of designers responsible for creative ideas in organizational structures. The main reason for this is a limited access to big advertising budgets that make it is possible to maintain creative specialists. Although such entities often benefit from the work of independent designers, their cooperation is threatened by poor quality of the offered ideas. Advertising agencies in the described group less often add additional services to the creative core and, in turn, focus only on 
providing ideas. Usually their offer is limited to graphic designs, preparation of advertising texts, or the basis of visual identification systems.

Limitations of both types of advertising agencies are related first and foremost to the crucial resource that, in described services, is creativity. A characteristic feature of this resource is that it is not related to a particular profession, education, or place of residence. Creativity is dispersed in the crowd and its acquisition requires creation of a favourable co-operation between the parties: the designer and the contractor of the creative service.

The answer to the above-mentioned challenge is crowdsourcing. Following the definitions of J. Howa (2006) G. Kazai (2011) and M. Poetz (Poetz, Schreier, 2012), crowdsourcing can be described as an enterprise's or institution's activity leading to acquisition of dispersed resources belonging to heterogeneous crowd by means of online public inquiry. Such resources may be information, knowledge, experience, ideas, skills, free time, work, or financial resources.

One of the key resources for crowdsourcing is creativity, understood here as an ability to solve problems and create ideas for a new product, graphic design, logo, advertising message, etc. In principle, crowdsourcing provides more creative ideas than other traditional and previously applied methods. This concept allows organizations to access a rare type of resource, which is creativity of dispersed creators, whose ideas, skills, and remarks have been so far undervalued and unused (Brabham, 2008). The examples analysed in the literature suggest that a large amount of ideas and hidden knowledge allow organizations to discover new patterns and trends that are important from the point of view of a potential recipient (Howe, 2008). The use of crowdsourcing has a positive effect on the efficiency and speed of generating ideas. The combination of the number of participants, creativity and passion, provides many interesting ideas quickly. Consequently, the short time spent on creating new ideas has a significant impact on the business process efficiency.

The use of crowdsourcing however, requires fulfilment of specific conditions (Howe, 2008):

1. Properly defined crowd characteristics. Depending on the resource that is planned to be acquired and the complexity of the ordered task, both the size and the characteristics of the crowd may vary.

2. A precisely described task, which is the basis for the execution of the order by the crowd.

3. Well-chosen tools and technologies for a two-way flow of information.

4. Preparation and selection of a public inquiry form.

5. Preparation of a remuneration system for completed and accepted tasks.

Implementation of crowdsourcing requires from an enterprise to not only prepare proper conditions described above, but also to be more open and go beyond the patterns existing in the organization.

Crowdsourcing is currently being intensively developed in the following areas (Petavy, 2017):

1. Innovation: product, service, experience or business model innovation.

2. Marketing \& communications: Brand strategy (naming, identity), communications (positioning, communications platforms, creative development), Activation and promotions.

3. Design: Design (packaging, point of sale, retail).

Research carried out in 2016 showed that the ideas derived from the crowd by means of crowdsourcing were implemented in (Petavy, 2017):

- $59 \%$ in the area of innovations,

- $34 \%$ in the area of marketing-communication activities,

- $7 \%$ in the area of design. 


\section{The use of crowdsourcing plattiorms on advertising service market}

Crowdsourcing platforms that are tailored to the purpose of business activity and character of acquired resources are employed in business (Galizia, Garibaldi, 2014). Using crowdsourcing platforms to acquire and offer creative ideas for advertising products is becoming more and more common. Examples of this type of phenomenon are crowdsourcing platforms that have been operating for over a decade, described below as creative agencies.

Crowdsourcing platform is a business model that enables the acquisition of distributed resources from the crowd for a specific purpose and in a specific business area. In case of advertising services, for which creativity is a key resource when using these platforms, special attention should be paid to the following elements.

The type and characteristics of crowd. When talking about creative services offered by crowdsourcing platforms, it is essential to provide the customer with the best ideas for graphic design or advertising text. Making use of a crowd of creative designers allows platforms to deliver a greater number of ideas that are more diverse. This is possible thanks to the applied rule saying that creativity may come from anyone, regardless of education, profession, or geographic location. Such approach creates a society of passionate people who eagerly share their creativity and can create interesting projects. Of great importance is also the fact that projects are created in parallel and that their creators have no contact with each other. This increases the chances of creating many independent, varied proposals for the client.

Well-defined objective. The concept of engaging crowd in action requires a person ordering to precisely define the task. In case of creative services related to creating graphic ideas, it is necessary to develop a proper description of the task.

Specified way to invite the crowd to cooperate. In case of the discussed services, contests constitute a form of a public inquiry. Participation in a contest is voluntary and does not guarantee a gratification. Creators decide themselves if they want to take part in the ordered task based on its description.

Well-chosen technologies. Works implemented on crowdsourcing platforms require properly selected technical solutions. The choice of technology affects communication efficiency and security of transactions.

Legal procedures. Given the character of the conducted services, preparation of legal procedures that facilitate management of intellectual property and acquisition of projects also becomes of particular importance. Crowdsourcing platforms implement the principle of confidentiality using the following solutions:

- contestants sign confidentiality agreements,

- use of market ideas requires signing an agreement on transfer of copyrights.

Remuneration for specific and sold projects. In case of crowdsourcing platforms that offer creative services, an important gratification is payment for the winning project. Remuneration usually falls into the range of 1,000 to $€ 10,000$ divided among the best designers (Petavy, 2017). Apart from the financial incentives, the possibility to present one's works created on the platform and outside it to potential buyers is equally important.

The above-mentioned requirements are only the basis for the creation of models of crowdsourcing platforms operating in the creative service sector. Nevertheless, it should be noted that what distinguishes crowdsourcing platforms operating in the described way is the great number of acquired ideas and short time of project completion. Crowdsourcing platforms chosen for exemplification have been designed on the basis of independent rankings. 
Table 1. Leading crowdsourcing platforms in the advertising service market

\begin{tabular}{llcll}
\hline \multicolumn{1}{c}{$\begin{array}{c}\text { Crowdsourcing platform/ } \\
\text { year of creation }\end{array}$} & \multicolumn{1}{c}{ Advertising service offer } & $\begin{array}{l}\text { Number of designers } \\
\text { and authors (crowd) }\end{array}$ & Customer & $\begin{array}{c}\text { Number of clients/number } \\
\text { of completed projects }\end{array}$ \\
\hline $\begin{array}{l}\text { https://www.crowdspring.com } \\
\text { Year 2008 }\end{array}$ & $\begin{array}{l}\text { Logo design, website design, } \\
\text { web content }\end{array}$ & 205,000 & $\begin{array}{l}\text { Service for small } \\
\text { companies }\end{array}$ & 40 thousand/53 thousand \\
\hline $\begin{array}{l}\text { https://99designs.com } \\
\text { Year 2008 }\end{array}$ & $\begin{array}{l}\text { Logo, websites, publishing, packaging, } \\
\text { labels, illustrations, clothes }\end{array}$ & $1,500,000$ & $\begin{array}{l}\text { Small and medium- } \\
\text { sized companies }\end{array}$ & $\begin{array}{l}444 \text { thousand/500 } \\
\text { thousand }\end{array}$ \\
\hline $\begin{array}{l}\text { http://www.designhill.com } \\
\text { Year 2014 }\end{array}$ & $\begin{array}{l}\text { Logo, websites, packaging, labels, } \\
\text { illustrations, clothes }\end{array}$ & 39,000 & $\begin{array}{l}\text { Small and medium- } \\
\text { sized companies }\end{array}$ & Several hundred \\
\hline $\begin{array}{l}\text { https://en.eyeka.com } \\
\text { Year 2006 }\end{array}$ & Wide range of dedicated solutions & 350,000 & Big companies & Several hundred/882 \\
\hline $\begin{array}{l}\text { https://tongal.com } \\
\text { Year 2009 }\end{array}$ & Video content & 120,000 & Big companies & Unknown
\end{tabular}

Source: own work based on: www.crowdsspring.com, www.99designs.com, www.designhill.com, www.eyeka.com, www.tongal.com.

Based on the crowdsourcing platforms presented in the above table two different business models can be distinguished. In the first model, implemented by e.g. CrowdSPRING, 99design, Designhill, and Tongal, the crowdsourcing platform manages the entire creative process, from gaining ideas to realizing them. A great advantage of this type of platforms is, first and foremost, creative resources of designers who number around 1.5 million in case of $99 \mathrm{design}$, and several hundred thousand participants in case of the other described platforms. Access to creative potential is possible only from the platform, which, in this case, is an active intermediary between the parties. Similarities between the described platforms from the point of ordering party are presented below:

- scope of offered services,

- degree of legal protection,

- guarantee of satisfaction with the purchased creative projects,

- short order execution time,

- specified price for the offered services-packages,

- communication between the ordering party and the designer takes place only through tools shared on the platform.

Similarities between the functioning of platforms from the perspective of the service provider (the designer) are mainly:

- designers' participation in the project is based on the idea of a competition,

- gratification is determined before the task begins,

- protection of intellectual property is clearly defined and specified,

- portfolios and profiles of designers are available on the platform,

- completed projects are also available on the platform.

The differences in the activities of the analysed platforms are not as prominent as the aforementioned similarities. It is possible to find features that, at a marketing level, distinguish the offer. For example, the crowdsourcing platform CrowdSPRING links the price of the package to the level of security and confidentiality of the obtained and transferred information. Thus, it points out the essence of legal protection of the prepared projects. The largest platform, 99designs, links the price to the number and quality of designers, additionally emphasizing the speed of execution and staying within the determined budget. This is a big advantage when compared to traditional advertising agencies that rarely assure meeting the determined budget at the stage of offer. Another platform, one 
that has been operating on the market for the shortest span of time, Designhill, is characterized by great efficiency and low prices. Its packages are mainly limited in regards to the number of designers.

In the case of the first described cooperation model, the buyers, i.e. the representatives of small and mediumsize companies, gain access to a vast number of interesting and diverse advertising projects that are executed in a short time. Another advantage of these types of platforms is the guaranteed fixed price of the order execution. The number of accomplished projects with the participation of a multitude of designers enabled the analysed entities to achieve profits significantly higher than local agencies. The prices of services offered by crowdsourcing platforms are usually included in packages with a value between USD 100 and USD 1,000. As to the benefits of the designers, the main advantage is the access to a market of potential buyers located in different regions of the world. Moreover, it is the prepared project proposal and not the designer's competence that goes through assessment. The downside of the aforementioned model is mostly the lack of professional advice at the stage of project selection. The buyers must decide on their own, which, together with the lack of experience and knowledge, may result in a wrong choice.

Another model of cooperation is the so-called community model (Petavy, 2017). An example of use of this model is the crowdsourcing web platform eYecka. Community models:

- allow access to a highly motivated creative community,

- provide the tools and IT technologies to facilitate the flow of information,

- organize and control the course of competitions, and select projects,

- develop financial and legal frames for cooperation.

eYecka platform, unlike the model mentioned before, offers its customers advice and support at various stages of cooperation with creators. Both buyers and creators are moderated by the platform staff in order to achieve the best final results. Inquiries from buyers are discussed in detail and refined before being submitted to execution. Projects submitted by creators undergo internal pre-selection and evaluation by eYecka employees. This platform has a developed system of cooperation, evaluation, and selection of projects submitted by thousands of designers and members of a creative crowd.

Both models of crowdsourcing platforms provide a perfect solution for an effective acquisition of creative ideas. The number of implemented ideas, creators involved, as well as the short project execution time, make these solutions a viable opportunity for the development of the creative service sector.

\section{Conclusion}

The concept of crowdsourcing applied in the creative service sector provides an unprecedented access to creativity dispersed in a crowd. Creativity, as the core of the advertising service, has been freed from the organizational constraints of a company and has become its authentic resource. Utilizing this potential becomes not only a great opportunity, but also a challenge for the advertising agencies as entities in the creative service market. Regardless of size and location, advertising agencies can use crowdsourcing to provide their customers with new, creative ideas for advertising actions in a shorter time and at a lower cost. This kind of approach facilitates access to high quality advertising products for a bigger group of small and medium-size companies as buyers, which has a positive impact on new operating conditions of entities. The creators themselves have become more important, as their work, until recently merely a hobby or additional activity, has become a valuable resource.

Advertising agencies that use crowdsourcing may apply different models of action. In business practice, both the integrated model, such as crowdsourcing platforms that offer a standardized offer for creative services, and 
the hybrid model, exemplified by community platforms, are applicable and effective. The hybrid model can be an incentive to move beyond the rigid framework of division between local and global agencies for entities operating so far in the traditional way in the advertising market. Hybrid agencies combine the strategic knowledge of their employees with the external resources of creative communities. In this arrangement, the employees of the agency remain in their role of the designers' work coordinators. The only difference is that they have access to unlimited creative ideas resources, which highly increases the chance to meet the needs of demanding customers.

In the context above, crowdsourcing becomes a solution to overcome the existing limitations in the creative service sector. This particularly applies to improvement of quality in case of creation of unique ideas. As indicated by the conducted research, this is the most desired feature of any good advertising service.

\section{References}

Brabham, D.C. (2008). Crowdsourcing as a Model for problem solving. The International Jurnal of Research into New Media Technologis, 1 (14), 75-90.

Galizia, T., Garibaldi, C. (2014). Tech trends 2014. Inspiring disruption. Deloitte University Press.

Howe, J. (2006). The rise of Crowdsourcing. Wired Magazine, 6 (14), 1-5.

Howe, J. (2008). Crowdsourcing. New York: Crown Publishing Group.

Kazai, G. (2011). In search of quality in crowdsourcing for search engine evaluation. Computer Science, 11 (66), $165-176$.

Poetz, M.K., Schreier, M. (2012). The value of crowdsourcing: Can user relly compete with professionals in generating new product ideas? Jurnal of Product Innovation Management, 29, 245-256.

Petavy, F. (2017). The age of ideation. Crowdsourcing report 2017 - eYeka, 3-36.

Cite this article aS: Szwajlik, A. (2018). Crowdsourcing as a challenge for advertising agencies in the creative service market. European Journal of Service Management, 2 (26), 257-263. DOI: 10.18276/ejsm.2018.26-32. 